\title{
PENGARUH CITRA DAN STORE ATMOSPHERE TERHADAP KEPUASAN PELANGGAN
}

\author{
SULFIANTI \\ RAHMAT MUBARAQ \\ HARIFUDDIN THAHIR \\ Jurusan Manajemen, Fakultas Ekonomi, Universitas Tadulako \\ Email: antisiulfianti@yahoo.com
}

\begin{abstract}
This study aims to find and analyze: (1) Significant influence of image and store atmosphere variable to customer satisfaction RM Radja Penyet Mas Fais Cab. Ahmad yani Palu, (2) The significant effect of image variable on customer satisfaction RM Radja Penyet Mas Fais Cab. Ahmad yani Palu, (3) Significant influence of store atmosphere variable to customer satisfaction RM Radja Penyet Mas Fais Cab. Ahmad yani Palu.The type of research used is causality (shows the relationship between variables). The populations that become the object in this study are the customers RM Radja penyet Mas Fais Cab.Ahmad Yani that can not be determined and unclear. Sampling technique in this study using purposive sampling, with the number of samples of 100 respondents. Data collection using questionnaires that have been tested for validity and reliability. The method of analysis using multiple regression analysis. The results showed (1) image and store significant atmosphere to customer satisfaction in RM Radja Penyet Mas Fais Cab. Ahmad Yani Palu, (2) Citra angry significant to customer satisfaction in RM Radja Penyet Mas Fais Cab. Ahmad Yani Palu, (3) Storing a significant response to customer satisfaction at RM Radja Penyet Mas Fais Cab. Ahmad Yani Palu.
\end{abstract}

Keywords: Image, Store Atmosphere.

ABSTRAK
Penelitian ini bertujuan untuk mengetahui dan menganalisa: (1) Pengaruh signifikan variabel citra dan suasana simpan terhadap kepuasan pelanggan RM Radja Penyet Mas Fais Cab. Ahmad yani Palu, (2) Pengaruh signifikan variabel citra terhadap kepuasan pelanggan RM Radja Penyet Mas Fais Cab. Ahmad yani Palu, (3) Pengaruh signifikan variabel suasana toko terhadap kepuasan pelanggan RM Radja Penyet Mas Fais Cab. Ahmad yani Palu. Jenis penelitian yang digunakan adalah kausalitas (menunjukkan hubungan antarvariabel) .Populasi yang menjadi obyek dalam penelitian ini adalah para pelanggan RM Radja penyet Mas Fais Cab.Ahmad Yani yang tidak dapat ditentukan dan tidak jelas. Teknik penarikan sampel dalam penelitian ini menggunakan purposive sampling, dengan jumlah sampel sebanyak 100 responden. Pengambilan data menggunakan kuesioner yang telah diuji validitas dan reliabilitasnya. Metode analisis menggunakan analisis regresi berganda. Hasil penelitian menunjukkan (1) Citra dan toko suasana signifikan terhadap kepuasan pelanggan di RM Radja Penyet Mas Fais Cab. Ahmad Yani Palu, (2) Citra marah signifikan terhadap kepuasan pelanggan di RM Radja Penyet Mas Fais Cab. Ahmad Yani Palu, (3) Menyimpan suasana tanggap signifikan terhadap kepuasan pelanggan di RM Radja Penyet Mas Fais Cab. Ahmad Yani Palu.

Kata Kunci: Citra, Store Atmosphere.

\section{PENDAHULUAN}

Bisnis rumah makan adalah bisnis yang memadukan antara produk dan layanan. Desain bangunan, interior dan eksterior gedung serta, atmosphere yang tercipta di dalam rumah makan, serta makanan dan minuman yang dijual beserta keseluruhan fasilitas yang ada merupakan contoh produk yang dijual. Sedangkan layanan yang dijual adalah keramah-tamahan karyawan dalam melayani pelanggannya. Banyak hal yang dapat mempengaruhi maju mundurnya usaha kuliner, salah satunya 
adalah bagaimana pihak manajemen dapat menarik pelanggan dan mempertahankan mereka dengan cara menciptakan citra dan store atmosphere rumah makan yang terbaik agar para tamu puas terhadap layanan yang diberikan. Persaingan bisnis sekarang ini, citra perusahaan dan store atmosphere merupakan hal yang paling penting bagi perusahaan untuk strategi diferensiasi ketika mereka menjual produk yang sama. Disamping citra yang baik, store atmosphere juga turut berperan dalam menjaring konsumen. Store atmosphere Menurut Kotler \& Keller (2008), identitas sebuah perusahaan dapat dikomunikasikan kepada pelanggan melalui dekorasi, atau secara lebih luas dari suasananya. Meskipun sebuah store atmosphere tidak secara langsung mengkomunikasikan kelas sosial dari produk-produk yang ada di dalamnya, sehingga hal ini dapat dijadikan alat untuk membujuk pelanggan menggunakan jasa tersebut. Adapun tujuan penelitian ini adalah untuk mengetahui pengaruh signifikan variabel citra dan store atmosphere terhadap kepuasan pelanggan RM Radja Penyet Mas Fais Cab. Ahmad yani Palu, pengaruh signifikan variabel citra terhadap kepuasan pelanggan RM Radja Penyet Mas Fais Cab. Ahmad yani Palu, pengaruh signifikan variabel store atmosphere terhadap kepuasan pelanggan RM Radja Penyet Mas Fais Cab. Ahmad yani Palu.

\section{KAJIAN LITERATURE}

\section{Pemasaran}

Menurut Kotler dan Keller (2016:27) Marketing is about identifying and meeting human and social needs. Maksudnya pemasaran adalah tentang mengidentifikasi dan memenuhi kebutuhan manusia dan sosial. The American Marketing Association dalam Kotler dan Keller (2016:27) mengemukakan bahwa: Marketing is the activity, set of institutions, and processes for creating, communicating, delivering, and exchanging offerings that have value for customers, clients, partners, and society at large. Maksudnya pemasaran adalah sebuah aktivitas, mengatur lembaga, dan serangkaian proses untuk menciptakan, mengkomunikasikan, menyampaikan, dan memberikan nilai kepada pelanggan, klien, mitra, dan masyarakat pada umumnya.

\section{Citra Perusahaan}

Defenisi citra menurut Kotler Keller (2012: 274), yaitu: Citra merupakan seperangkat keyakinan, ide, dan kesan yang dimiliki oleh seorang terhadap suatu objek. Sedangkan menurut Gregory (2011: 63) dalam bukunya Marketing Coorporate Image, citra perusahaan merupakan kombinasi dampak terhadap observer dari semua komponen-komponen verbal maupun visual perusahaan baik yang direncanakan ataupun tidak atau dari pengaruh eksternal lainnya.

\section{Jenis-Jenis Citra Perusahaan}

Frank Jefkins menyebutkan beberapa jenis citra (image). Berikut adalah lima jenis citra yang dikemukakan, yakni:
a. Citra bayangan (mirror image)
b. Citra kini (Current Image)
c. Citra harapan (Wish Image)
d. Citra perusahaan (Coprporate Image)
e. Citra serbaneka (Multiple Image)
f. Citra penampilan (Performance Image)

\section{Store Atmosphere}

Gilbert dalam Dessyana (2013: 846) mendefinisikan Store atmosphere merupakan kombinasi dari pesan secara fisik yang telah direncanakan, Store atmosphere dapat digambarkan sebagai perubahan terhadap perencanaan lingkungan pembelian yang menghasilkan efek emosional khusus yang dapat menyebabkan pelanggan melakukan tindakan pembelian. Levy and Weitz dalam Dessyana (2013: 846) mengemukakan bahwa Store atmosphere merupakan penciptaan suasana melalui visual, 
penataan, cahaya, musik, dan aroma yang dapat menciptakan lingkungan pembelian yang nyaman sehingga dapat mempengaruhi persepsi dan emosi pelanggan untuk melakukan pembelian.

\section{Cakupan Store Atmosphere}

Menurut Barry dan Evans (2010) cakupan store atmosphere meliputi:

\section{1) Exterior (bagian luar)}

Karakteristik exterior mempunyai pengaruh yang kuat pada citra tersebut, sehingga harus direncanakan dengan sebaik mungkin. Kombinasi dari exterior ini dapat membuat bagian luar menjadi terlihat unik, menarik, menonjol, dan mengundang orang untuk masuk dalam, adapun elemen-elemennya adalah:

a) Storefont (bagian muka)

Storefront adalah bagian depan dari sebuah toko. Bagian depan dari sebuah toko didesain sedemikian rupa sehingga dapat menarik minat bagi konsumen untuk masuk ke dalam toko dan kemudian melakukan pembelian.

b) Marque (simbol)

Marquee adalah suatu tanda yang terletak di depan toko yang memberikan ciri khas tersendiri bagi toko. Marquee yang berbeda dengan toko yang lain akan menarik dan mengundang perhatian konsumen untuk masuk ke dalam toko. Tanda pada marquee adalah tulisan, logo toko. Marquee dapat dibuat dengan menggunakan teknik pewarnaan, tulisan serta dapat juga menggunakan lampu neon.

c) Extrance (pintu)

d) Display window (tampilan jendela)

e) Height and size building (tinggi dan ukuran gedung)

f) Uniqueness (keunikan)

g) Surrounding area (lingkungan sekitar)

h) Parking (tempat parkir)

2) General Interior (bagian dalam)

General interior dimana terdiri dari warna lantai dan cahaya, aroma dan suara (musik), tekstur dinding, suhu ruangan, lebar antara ruangan satu dengan ruangan lainnya,tingkat pelayan dan harga. Elemen penataan general interior penting karena posisi inilah biasanya pengambilan keputusan untuk membeli diambil sehingga akan mempengaruhi jumlah penjualan. Penataan yang baik yaitu yang dapat menarik perhatian pengunjung dan membantu mereka agara mudah mengamati, memeriksa dan memilih barang-barang itu dan akhirnya melakukan pembelian. Ketika konsumen masuk kedalam toko, ada banyak hal yang akan mempengaruhi persepsi mereka pada toko tersebut.

3) Layout ruangan (tata letak)

Pengelola harus mempunyai rencana dalam penentuan lokasi dan fasilitas. Pengelola juga harus memanfaatkan ruangan yang seefektif mungkin, hal-hal yang perlu diperhatikan dalam perancangannya meliputi:

a) Allocation of floor space for selling, personal, and customer.

b) Traffic flow

c) Interior point of interest display (dekorasi pemikat)

Store atmosphere diukur dengan indikator menurut Barry dan Evan (2010) antara lain:

1) Exterior (bagian luar) yang merupakan pengaturan tata letak berbagai fasilitas 
diluar ruangan, termasuk tempat parkir yang aman, papan nama, jalan masuk, etalase, tinggi toko, dan ukuran toko.

2) Interior (bagian dalam) merupakan kondisi dari dalam ruangan, termasuk suhu udara dan musik untuk membuat suatu kenyamanan bagi pelanggan.

3) Store Layout (tata letak ruangan) meliputi penataan penempatan ruang untuk mengisi luas lantai yang tersedia, mengklasifikasikan produk yang akan ditawarkan, pengaturan lalu lintas di dalam toko, pengaturan lebar ruang yang dibutuhkan, pemetaan ruangan toko dan menyusun produk yang ditawarkan secara individu.

4) Interior display (pajangan) merupakan dekorasi pemikat yang meliputi tanda petunjuk dan pemasangan poster-poster guna menarik perhatian pelanggan. Bertujuan untuk memberikan informasi pada konsumen yang berbelanja, merupakan tambahan untuk memberikan kesan berbeda pada store atmosphere dan berfungsi sebagai alat promosi.

\section{Kepuasan Pelanggan}

Menurut Kotler \& Keller (2009) kepuasan pelanggan adalah perasaan senang atau kecewa seseorang yang timbul karena membandingkan kinerja yang dipresepsikan produk (atau hasil) terhadap ekspektasi mereka. Artinya bahwa kepuasan adalah perasaan senang, puas individu karena antara harapan dan kenyataan dalam memakai dan pelayanan yang diberikan terpenuhi. Bagi perusahaan yang berpusat pada pelanggan, kepuasan pelanggan merupakan tujuan dan sarana perusahaan. Jumlah pesaing yang semakin banyak mengharuskan perusahaan-perusahaan yang ada untuk mempunyai strategi khusus dalam bersaing, bertahan hidup serta berkembang. "Kepuasan adalah perasaan senang atau kecewa seseorang yang timbul karena membandingkan kinerja yang dipersepsikan produk (atau hasil) terhadap ekspektasi mereka" (Kotler \& Keller, 2009:138).

\section{Kerangka Pemikiran}

1. Pelayanan

\section{Citra (X1)}

2. Harga

3. Kualitas

4. Lingkungan fisik Suryandari (2003:3)

1. Exterior (bagian luar)

2. Interior (bagian dalam)

3. Store Layout (tata letak ruangan)

4. Interior display (pajangan)

Barry dan Evan (2010)

\section{Gambar 1}

\section{Kerangka Pemikiran}

$-\mathbf{-} \rightarrow$ Berpengaruh secara parsial

$\rightarrow$ Berpengaruh secara simultan 
Hipotesis disusun berdasarkan teori dan kerangka berpikir yang sudah diuraikan sebelumnya, maka dari teori dan kerangka berpikir diatas dapat disusun beberapa hipotesis sebagai berikut:

1. Terdapat pengaruh signifikan variabel citra dan store atmosphere terhadap kepuasan pelanggan pada RM Radja Penyet Mas Fais Cab. Ahmad yani Palu.

2. Terdapat pengaruh signifikan variabel citra terhadap kepuasan pelanggan pada RM Radja Penyet Mas Fais Cab. Ahmad yani Palu.

3. Terdapat pengaruh signifikan variabel store atmosphere terhadap kepuasan pelanggan pada RM Radja Penyet Mas Fais Cab. Ahmad yani Palu.

\section{METODE PENELITIAN}

Jenis penelitian yang digunakan dalam penelitian ini adalah penelitian kausalitas. penelitian kausalitas adalah penelitian yang dilakukan untuk menggambarkan skema hubungan dan pengaruh dua variabel atau lebih, serta bagaimana satu variabel mempengaruhi variabel lainnya Jenis data yang digunakan dalam penelitian ini adalah data primer. Sumber data primer dalam penelitian ini diperoleh langsung dari para pelanggan RM Radja penyet Mas Fais Cab. Ahmad Yani. Teknik pengambilan dan pengumpulan data yang dilakukan dengan cara kuesioner dan Wawancara.

Populasi yang menjadi obyek dalam penelitian ini adalah para pelanggan RM Radja penyet Mas Fais Cab.Ahmad Yani yang jumlahnya tidak terbatas. Jumlah populasinya tidak diketahui secara pasti maka untuk menentukan besarnya sampel yaitu dengan menggunakan rumus Frendy dalam Ekasari (2014: 98)

$$
\mathrm{n}=\frac{\mathrm{Z}^{2}}{4 \mu^{2}}
$$

Keterangan:

$\mathrm{n}=$ ukuran sampel

$\mathrm{Z}=$ tingkat keyakinan sampel yang dibutuhkan dalam penelitian, pada $\alpha=5 \%$

(derajat keyakinan ditentukan 95\%) maka $\mathrm{Z}=1,96$

$\mu=$ margin of error, tingkat kesalahan yang dapat ditolerir (ditentukan 10\%)

Menggunakan rumus diatas, maka diperoleh perhitungan sebagai berikut:

$$
\begin{aligned}
& \mathrm{n}=\frac{1,96^{2}}{4(0,1)^{2}} \\
& \mathrm{n}=96,4=97 \approx 100 \text { responden }
\end{aligned}
$$

Penelitian ini menggunakan aplikasi software SPSS (Statistical Program for Social Scane) versi 16.0 yang dipakai untuk menganalisis pengaruh secara simultan dan pengaruh secara parsial variabel independen terhadap dependen. Teknik analisis data yang dipergunakan dalam penelitian ini, untuk mengukur dan menganalisis besarnya hubungan kualitas dan harga produk terhadap kepuasan konsumen menggunakan produk Tupperware di Kota Palu, menggunakan alat analisis statistic parametric regresi linear berganda (Multiple Regression Analisis). Menurut Sugiyono (2014:277) bahwa model umum bentuk persamaan alat analisis statistic parametric regresi linear berganda dapat digambarkan sebagai berikut persamaan struktural dalam model sebagai berikut:

$\mathbf{Y}=\mathbf{a}+\mathbf{b}_{1} \mathbf{x}_{1}+\mathbf{b}_{2} \mathbf{x}_{2}+\mathbf{e}$

Dimana:

$\mathrm{Y}=$ Kepuasan Pelanggan

$\mathrm{X}_{1}=$ Citra

$\mathrm{X}_{2}=$ Store Atmosphere

$\mathrm{A}=$ Konstanta

$\mathrm{b}_{1-} \mathrm{b}_{2}=$ Koefisien Regresi 


\section{HASIL DAN PEMBAHASAN}

Analisis Regresi Berganda

\section{Tabel 1}

Hasil Analisis Regresi Linear Berganda

\begin{tabular}{|c|c|c|c|c|c|}
\hline \multicolumn{6}{|c|}{ Dependen Variabel Y = Kepuasan Pelanggan } \\
\hline \multirow[t]{2}{*}{ Variabel Independen } & \multicolumn{2}{|c|}{$\begin{array}{c}\text { Unstandardized } \\
\text { Coefficients }\end{array}$} & \multirow{2}{*}{$\begin{array}{c}\begin{array}{c}\text { Standardized } \\
\text { Coefficients }\end{array} \\
\text { Beta }\end{array}$} & \multirow[t]{2}{*}{$\mathbf{t}$} & \multirow[t]{2}{*}{ Sig } \\
\hline & B & $\begin{array}{l}\text { Standar } \\
\text { Error }\end{array}$ & & & \\
\hline $\mathrm{C}=$ Constanta & .195 & .182 & & 1.073 & .286 \\
\hline Citra $\left(\mathrm{X}_{1}\right)$ & .208 & .050 & .186 & 4.138 & .000 \\
\hline Store atmosphere $\left(\mathrm{X}_{2}\right)$ & .763 & .042 & .813 & 18.091 & .000 \\
\hline $\begin{array}{ll}\text { Multiple } \mathrm{R} & =.931 \\
\mathrm{R} \text { Square }\left(\mathrm{R}^{2}\right) & =.867\end{array}$ & & & $=.000$ & & \\
\hline
\end{tabular}

Hasil tersebut apabila ditulis dalam bentuk persamaan regresinya adalah sebagai berikut:

$$
\mathrm{Y}=0.195+\mathbf{0 , 2 0 8 X 1}+\mathbf{0 , 7 6 3} \mathrm{X2}
$$

\section{Pembahasan}

Adapun penjelasan bentuk persamaan tersebut adalah sebagai berikut:

1) Nilai Konstanta $Y$ (kepuasan pelanggan) sebesar 0.195. Artinya, jika nilai variabel citra $\left(X_{1}\right)$ dan store atmosphere $\left(\mathrm{X}_{2}\right)$ bernilai 0 , maka variabel dependen kepuasan pelanggan $(\mathrm{Y})$ sebesar 0.195. Setiap ada kenaikan pada variabel independen sebesar satu satuan maka akan meningkatkan variabel dependen sebesar nilai koefisien beta masing-masing variabel independen.

2) Koefisien regresi variabel citra $\left(X_{1}\right)$ sebesar 0,208. Artinya, jika ada kenaikan pada variabel citra $\left(\mathrm{X}_{1}\right)$ sebesar satu skala sikap maka variabel kepuasan pelanggan naik sebesar 0,208 skala sikap.

3) Koefisien regresi variabel store atmosphere $\left(\mathrm{X}_{2}\right)$ sebesar 0,763. Artinya, jika ada kenaikan pada variabel store atmosphere $\left(\mathrm{X}_{2}\right)$ sebesar satu skala sikap maka variabel kepuasan pelanggan naik sebesar 0,208 skala sikap.

Koefisien korelasi (R) memiliki nilai sebesar 0,931 yang berarti bahwa variabel yang diteliti yaitu citra dan store atmosphere mempunyai hubungan yang kuat dengan variabel terikatnya sebesar 0,931 atau sebesar $93,1 \%$.

\section{Variabel Citra $\left(\mathbf{X}_{1}\right)$}

Berdasarkan Tabel 1, hasil pengujian dengan SPSS diperoleh angka signifikansi sebesar 0,000. Angka $0,000<0,05$ oleh karena itu, hipotesis diterima. Hal ini berarti variabel $\mathrm{X}_{1}$ (citra) berpengaruh terhadap variabel Y (kepuasan pelanggan).

\section{Variabel Store atmosphere $\left(\mathrm{X}_{2}\right)$}

Berdasarkan Tabel 1, hasil pengujian dengan SPSS angka signifikansi sebesar 0,000. Angka 0,000 $<0,05$ oleh karena itu, hipotesis diterima. Hal ini berarti variabel $\mathrm{X}_{2}$ (store atmosphere) berpengaruh terhadap variabel Y (kepuasan pelanggan).

\section{Koefisien Determinasi $\left(\mathbf{R}^{2}\right)$}

Koefisien determinasi $\left(\mathrm{R}^{2}\right)$ pada intinya mengukur seberapa jauh kemampuan model dalam menerangkan variasi variabel dependen. Nilai koefisien determinasi adalah antara nol dan satu 
(Ghozali, 2001). Hasil perhitungan dengan menggunakan program SPSS versi 16 dapat diketahui bahwa koefisien determinasi yang diperoleh sebesar 0,867. Hal ini berarti 86,7\% kepuasan pelanggan dapat dijelaskan oleh variabel citra dan store atmosphere, sedangkan sisanya yaitu $13,3 \%$ kepuasan pelanggan dipengaruhi oleh variabel-variabel lainnya yang tidak diteliti dalam penelitian ini.

\section{KESIMPULAN DAN SARAN}

\section{Kesimpulan}

Berdasarkan hasil penelitian dan pembahasan, maka dapat ditarik kesimpulan sebagai berikut:

1. Citra dan store atmosphere berpengaruh signifikan terhadap kepuasan pelanggan di RM Radja Penyet Mas Fais Cab. Ahmad Yani Palu. Hal tersebut menunjukan bahawa citra dan store atmosphere yang baik akan membuat pelanggan merasa puas berdasarkan pengetahuan dan pengalaman yang mereka dapatkan.

2. Citra berpengaruh signifikan terhadap kepuasan pelanggan di RM Radja Penyet Mas Fais Cab. Ahmad Yani Palu. Hal tersebut berarti citra yang terdiri dari pelayanan, harga, kualitas dan fasilitas fisik telah memberikan kepuasan kepada pelanggan.

3. Store atmosphere berpengaruh signifikan terhadap kepuasan pelanggan di RM Radja Penyet Mas Fais Cab. Ahmad Yani Palu. Hal ini berarti store atmosphere yang terdiri dari Exterior, Interior, Store Layout, Interior Display yang terkonsep dengan baik, akan membuat rasa nyaman bagi pelanggan sehingga akan menciptakan kepuasan pelanggan.

\section{Saran}

Berdasarkan hasil penelitian, pembahasan dan kesimpulan yang diperoleh, maka saran yang dapat diberikan sebagai berikut:

1. Bagi Perusahaan

a) Hasil uji tanggapan responden pada variabel citra dengan indikator fasilitas fisik memadai menjadi indikator dengan nilai mean terendah, dan ini terbukti belum tersedianya fasilitas seperti meja dan kursi makan yang mencukupi, sehingga pelanggan yang datang harus menunggu beberapa waktu untuk mendapatkan meja dan kursi RPMF. Maka disarankan kepada RPMF sebaiknya selalu menjaga citra agar kepercayaan pelanggan dapat terjaga kepada perusahaan untuk dapat tetap menjadi rumah makan terbaik yang dapat membuat pelanggan puas. Menjaga citra dapat di mulai dengan memberikan nilai-nial positif bagi pelanggan seperti menangani dan memberikan solusi dengan cepat jika ada pelanggan yang tidak mendapatkan meja dan kursi makan.

b) Hasil uji tanggapan responden pada variabel store atmosphere dengan indikator penataan meja makan yang rapi menjadi indikator dengan nilai mean terendah, yang disebabkan karena meningkatnya jumlah pelanggan di RM Radja Penyet Mas Fais. Maka disarankan untuk pihak manajemen RPMF untuk tanggap dalam mengambil tindakan langsung berupa kerja dari semua pihak termasuk karyawan maupun pelanggan. misalnya penataan meja makan yang kurang rapi disebabkan ramainya pengunjung sehingga karyawan kesulitan untuk merapikan kembali meja makan tersebut.

c) Hasil uji tanggapan responden pada variabel kepuasan pelanggan dengan dua nilai mean terendah yaitu indikator pelayanan sesuai keinginan dan kinerja keseluruhan lebih baik dengan yang lain, hal ini menunjukan bahwa persepsi pelanggan terhadap kinerja secara keseluruhan di RM Radja Penyet Mas Fais belum unggul dibandingkan dengan yang lain, maka untuk mempertahankan kepuasan pelanggan, disarankan kepada pihak RPMF untuk melakukan pengukuran kepuasan pelanggan secara berkala 6 bulan sampai 1 tahun sekali sebagai bentuk pengendalian agar kepuasan pelanggan tetap terjaga. 


\section{REFERENSI}

Barry, Berman and Evans, Joel R. (2010). Retail Management: A Strategic Approach. $8^{\text {th }}$ Edition. Upper Saddle River: Pretice Hall International, Inc.

Consuegra, D., Molina A., dan Esteban A. (2007). An Integrated Model of Price, Satisfaction and Loyalty: An Empirical Analysis in Service Sector. Journal of Product and Brand Management, 16 (7): 459-468.

Dessyana, Cindy Juwita. (2013). Store Atmosphere Pengaruhnya TerhadapKeputusan Pembelian Konsumen Di Texas Chicken Multimart II Manado. Jurnal EMBA, Vol.1, No. 3, Hal. 844-852.

Ekasari, Novita. (2014). Pengaruh Promosi berbasis Social media terhadap keputusan pembelian produk jasa Pembiayaan kendaraan PT.BFI Finance Jambi. Jurnal Penelitian Seri Humaniora. Volume 16, Nomor 2, Hal. 81-102 ISSN: 0852-8349. Universitas Jambi.

Gregory, R. James \& Jack G. wiechhman. (2011). Pemasaran Ritel (Edisi kesebelas).

Kotler, Philip. (2008). Manajemen Pemasaran edisi kesebelas. Jilid 2, Edisi Bahasa Indonesia. Jakarta: Indeks.

Kotler, P.\& Keller. (2009). Manajemen Pemasaran edisi ke-13. Jakarta: Erlangga.

Kotler, P.\& Keller, K.L. (2012). Marketing Management (13th ed.). New Jersey : Prentice Hall, Inc.

Kotler, P. \& Keller, Kevin Lane. (2016). Marketing management. $15^{\text {th }}$ edition. England: pearson education, Inc.

Ghozali, Imam, (2001). Aplikasi Analisis Multivariate Dengan Program SPSS, Badan Penelitian Universitas Diponegoro, Semarang.

Sugiyono, (2014). Metodologi penelitian manajemen:Pendekatan Kuantitatif, Kualitatif, Kombinasi, Penelitian Tindakan dan Penelitian Evaluasi,Cetakan Ke-3. Bandung: Alfabeta. 